Research Article

\title{
Comparative study of efficacy and adverse effects profile of telmisartan vs enalapril maleate in patients of essential hypertension and diabetic hypertensives
}

\author{
Jhansivani $\mathrm{Ch}^{1 *}$, Chandrakala Kambar ${ }^{2}$, Shankar Kurli ${ }^{2}$
}

\begin{abstract}
${ }^{1}$ Department of Pharmacology, Guntur Medical College, Guntur -522002, Andhra Pradesh, India, ${ }^{2}$ Department of Pharmacology, Siddhartha Medical College, Vijayawada, Andhra Pradesh520008, India
\end{abstract}

Received: 23 December 2013

Accepted: 7 January 2014

*Correspondence to:

Dr. Jhansivani Ch,

Email: chandook2@gmail.com

(C) $2014 \mathrm{Ch} \mathrm{J}$ et al. This is an open-access article distributed under the terms of the Creative Commons Attribution NonCommercial License, which permits unrestricted noncommercial use, distribution, and reproduction in any medium, provided the original work is properly cited.

\begin{abstract}
Background: Hypertension is the most common cardiovascular disease and is one of the leading causes of morbidity and mortality. Hypertension when associated with Diabetes mellitus increases this risk. To prevent this, we need appropriate antihypertensive agents with better compliance. By virtue of selective inhibition of angiotensin II type 1 receptor, telmisartan reduces blood pressure throughout the day with high tolerability.

Methods: A longitudinal and interventional study was undertaken including both male and female patients within the age group of 25-55yrs with clinically diagnosed Essential hypertension and essential hypertension associated with type II diabetes mellitus. Totally 80 patients were enrolled in this study. They were divided into 2 groups i.e., Essential hypertension group as A and hypertension associated with diabetes group as B with 40 patients in each group. Again A group was divided into 2 sub-groups (A1 \& A2) and B into (B1 \& B2) with 20 patients in each group. A1and B1 sub groups received Tab. Telmisartan 40mg once a day. A2 and B2 sub groups received tab. Enalapril maleate $5 \mathrm{mg}$ once daily. The total period of the study was 3 months.

Results: In this study, both telmisartan and enalapril maleate reduced systolic and diastolic blood pressures in A and B groups at 2 weeks, 6 weeks, and 12 weeks almost equally with no statistical significance. But in terms of adverse effect profile, persistent dry cough and rash was observed more in A2 and B2 group than A1 and B1 subgroups.

Conclusions: Telmisartan is effective, better tolerated than enalapril for the treatment of hypertension.
\end{abstract}

Keywords: Hypertension, Diabetes mellitus, Telmisartan, Enalapril, Blood pressure, Cough

\section{INTRODUCTION}

Hypertension is the most common cardiovascular disease that affects about 1 billion individuals worldwide. Hypertension is twice common in persons with diabetes mellitus. The prevalence of diabetes mellitus in adults was around $4 \%$ worldwide. ${ }^{1}$ The latest BHS (British Hypertensive society) guidelines strongly recommended Angiotensin converting enzyme inhibitors (ACEIs) / Angiotensin receptor blockers (ARBs) as first line agents in hypertensive patients younger than 55 years of age including hypertension associated with diabetes mellitus. ${ }^{2}$
Albumin Excretion as a therapeutic markermicroalbuminuria is an early and reliable predictor of diabetic nephropathy in both type I - insulin dependent diabetes mellitus (IDDM) and type II - non insulin dependent diabetes mellitus (NIDDM) patients, nephropathy being characterised by hypertension and an inevitable decline in renal function. In addition to predicting nephropathy, in type II diabetes, microalbuminuria also predicts mortality, the major causes of death being related to cardiovascular disease. ACE inhibitors reduce microalbuminuria and, in the longer term, they are superior to conventional therapies in maintaining normal renal function. ARBs also appear to be renoprotective in diabetic patients. 
Previously many studies were done to compare the efficacy of ACEIs and ARBs either in hypertensive or diabetic or diabetic hypertensive patients but no study has compared their efficacy between hypertensives and diabetic hypertensives

In this scenario, the present study was taken up to compare the efficacy and safety of enalapril maleate (ACEI) and telmisartan (ARB) in patients of essential hypertension and essential hypertension associated with diabetes mellitus.

\section{Aim}

1. To compare the efficacy and adverse effect profile of telmisartan and enalapril maleate in essential hypertensive patients (group A) as 2 sub-groups A1 and $\mathrm{A} 2$ respectively and in diabetic hypertensive patients (group B) as 2 sub-groups B1 and B2 respectively.

2. To compare the systolic and diastolic blood pressure lowering effect in both the sub groups (A1 and A2) of essential hypertension.

3. To compare the systolic and diastolic blood pressure lowering effect in both the sub groups (B1and B2) of diabetic hypertensive patients.

4. To compare the incidence of adverse effects in both A and B groups.

5. To compare the incidence and levels of microalbuminuria in both $\mathrm{A}$ and $\mathrm{B}$ groups.

\section{METHODS}

This was a longitudinal and interventional study. The protocol was approved by the ethics committee of our college and written informed consent was taken from the patients in local language. Both male and female patients within the age group of 25-55yrs with clinically diagnosed essential hypertension and essential hypertension associated with type II diabetes mellitus attending medical OP in Government General Hospital, Vijayawada were included in this study.

Totally 80 patients were enrolled in this study. These patients were divided into 2 groups i.e., essential hypertension group (A) and diabetes associated with hypertension group (B) with 40 patients in each group. Again A group was divided into 2 sub-groups (A1 \& A2) with 20 patients in each group i.e., A1 sub group received Tab. Telmisartan 40mg once a day and A2 sub group received tab. Enalapril maleate $5 \mathrm{mg}$ once daily.

Similarily B group was divided into 2 subgroups (B1 \& B2) with 20 patients in each group. B1 sub group received tab. Telmisartan $40 \mathrm{mg}$ once a day and B2 sub group received tab. Enalapril maleate $5 \mathrm{mg}$ once daily.
The total period of the study was 3 months. Periodic recording of blood pressure was done for every two weeks. The blood pressure was measured in right hand, in sitting posture with arm supported at heart level.

\section{Inclusion criteria}

1. Males and females of age between 25 yrs-55 yrs. $^{2}$

2. Mild and moderate essential hypertensive patients and diabetic hypertensive patients with Systolic B.P. between $130-169 \mathrm{~mm} \mathrm{Hg}$ and diastolic BP between 90-109mmHg.

3. Diabetic hypertensive patients who are under glycemic control receiving oral hypoglycemic drugs.

4. Patients with history of hypertension without taking antihypertensive treatment for a period of one month.

\section{Exclusion criteria}

1. Males and Females age $<25$ yrs. And $>55$ yrs.

2. Pregnant \& lactating women.

3. Patients already on other antihypertensive drugs.

4. IDDM patients receiving insulin.

5. Patients with other conditions like severe hypertension, Hepatic failure, respiratory failure, renal failure, congestive heart failure and acute severe asthma.

6. Secondary hypertension.

7. Chronic use of corticosteroids, NSAIDS and sex hormones like oral contraceptives pills.

\section{Drugs}

Telmisartan (Telsartan) -40mg once daily -Dr. Reddy's Laboratories 1td; Enalapril maleate (Enam) - 5mg once daily -- Dr. Reddy's Laboratories ltd.

\section{Statistical analysis employed}

1. Chi-Square test.

2. Unpaired' $t$ ' test.

3. Paired ' $t$ ' test.

4. $\mathrm{P}$ value $<0.05$ was taken as significant.

\section{RESULTS}

After 2 weeks, 6 weeks and 12 weeks of therapy in essential hypertension group (A) systolic blood pressure reduction to normal level was seen in 12,15 and 17 patients in A1 group and 13,13 and 14 patients in A2 group respectively. Diastolic blood pressure reduction to normal levels was seen in 4, 10 and 14 in A1 and 3, 7 and 12 in A2 group respectively. 
After 2 weeks, 6 weeks and 12 weeks of therapy in Diabetic hypertension group (B) systolic blood pressure reduction to normal level was seen in 12,17 and 15 patients in B1 group and 10, 14 and 13 patients in B2 group respectively. Diastolic blood pressure reduction to normal levels was seen in 6, 7 and 13 in B1 and 3, 6 and 12 in B2 group respectively.

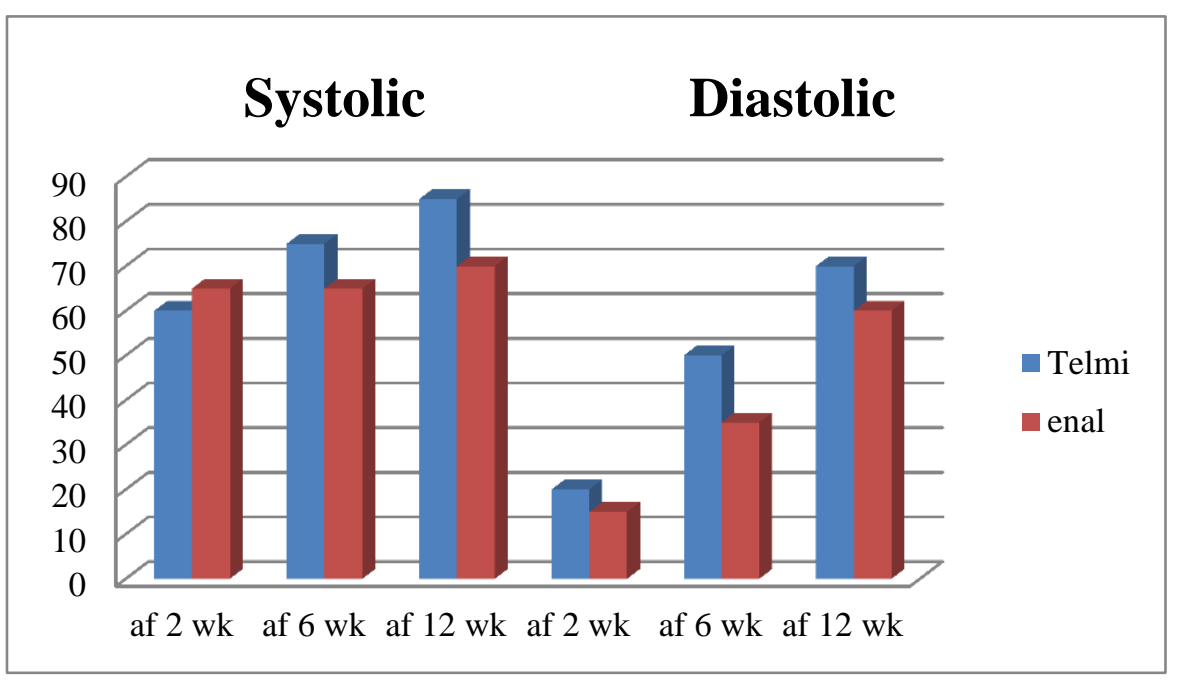

Figure 1: Percentage of patients who attained normal blood pressure after treatment in A1 and A2 groups.

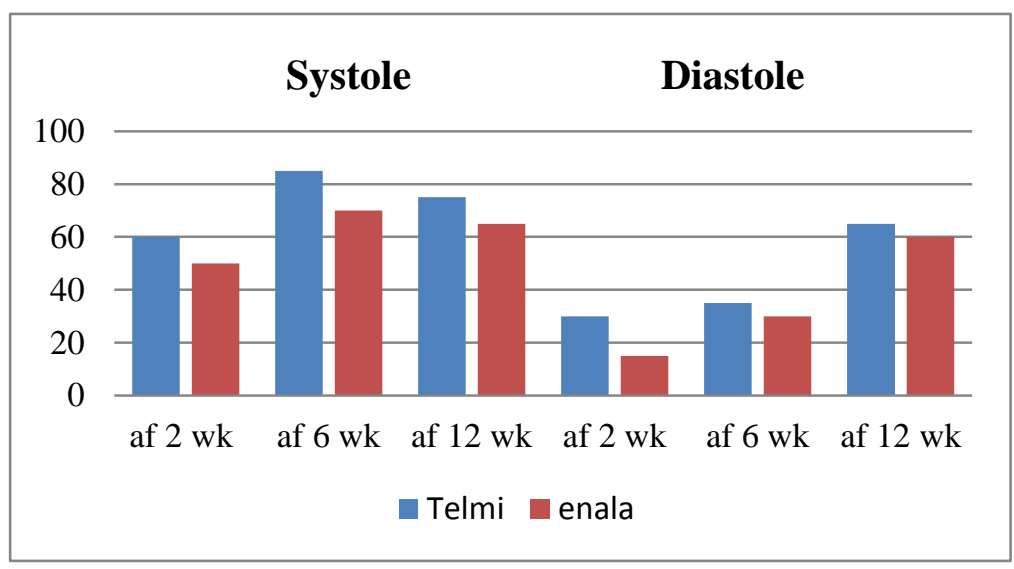

Figure 2: Percentage of patients who attained normal blood pressure after treatment in B1 and B2 groups.

Table 1: Mean reduction of BP in A group.

\begin{tabular}{|lllll|}
\hline Drug & $\begin{array}{l}\text { Baseline BP } \\
\text { (mm of Hg) }\end{array}$ & \multicolumn{3}{l|}{$\begin{array}{l}\text { Mean reduction of BP } \\
\text { (mm of } \mathbf{~ H g})\end{array}$} \\
\hline Telmisartan & & 2 wks & 6 wks & 12 wks \\
\hline Systolic & 143.5 & 9.5 & 14.5 & 20.5 \\
\hline Diastolic & 98.1 & 6.1 & 10.8 & 14.5 \\
\hline Enalapril & & & & \\
\hline Systolic & 155.5 & 10 & 13.4 & 19 \\
\hline Diastolic & 96.7 & 6.8 & 8.6 & 11.7 \\
\hline
\end{tabular}

Table 2: Mean reduction of $\mathrm{BP}$ in $\mathrm{B}$ group.

\begin{tabular}{|lllll|}
\hline Drug & \multicolumn{2}{l}{$\begin{array}{c}\text { Baseline BP } \\
(\mathbf{m m} \text { of Hg) }\end{array}$} & \multicolumn{2}{l|}{$\begin{array}{l}\text { Mean reduction of BP } \\
(\mathbf{m m} \text { of Hg) }\end{array}$} \\
\hline Telmisartan & & 2 wks & 6 wks & 12 wks \\
\hline Systolic & 144.3 & 10 & 12.8 & 20.3 \\
\hline Diastolic & 91.9 & 7.6 & 10.4 & 14.1 \\
\hline Enalapril & & & & \\
\hline Systolic & 146.5 & 7 & 17 & 19 \\
\hline Diastolic & 95.9 & 5.8 & 9 & 10.2 \\
\hline
\end{tabular}




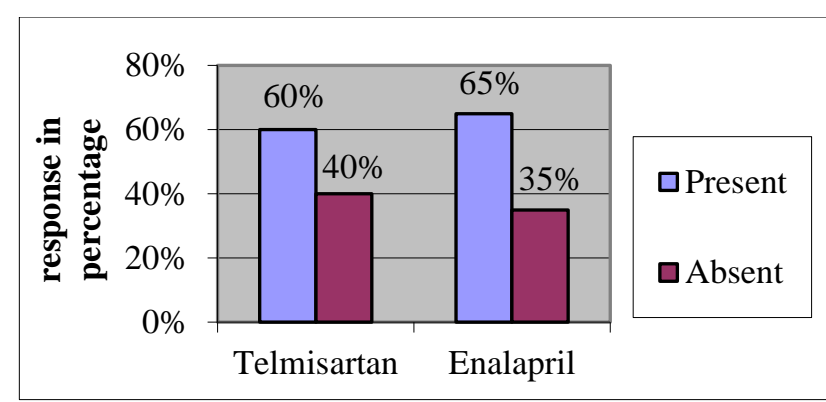

Figure 3: Percentage response in systolic blood pressure after 2 weeks in Group A.

$\chi^{2-0.106}$

$\mathrm{p}=>0.05$ not significant

Systolic unpaired ' $\mathrm{t}$ ' test $=0.295$ not significant. $(\mathrm{p}>0.05)$

Telmisartan paired ' $\mathrm{t}$ ' test for systolic $=7.20$ significant $(\mathrm{p}<0.05)$

Enalapril paired ' $\mathrm{t}$ ' test for systolic $=10$ significant $(\mathrm{p}<0.05)$

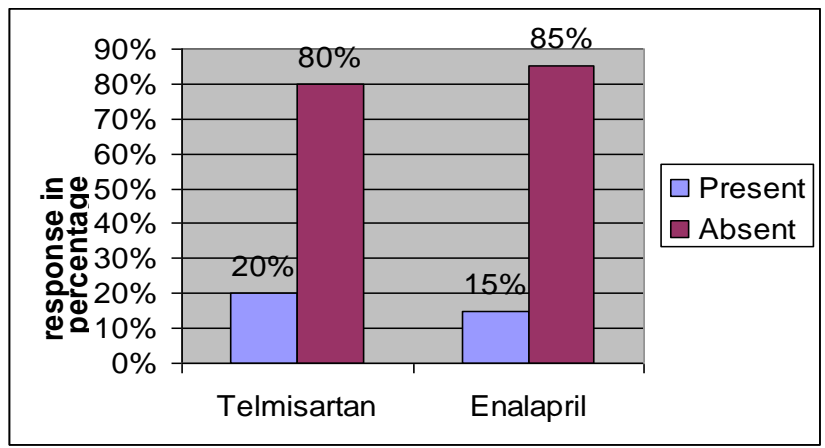

Figure 4: Percentage response in diastolic blood pressure after 2 weeks in Group A.

$\chi 2-0.622, \mathrm{p}=>0.05$ not significant

Diastolic unpaired ' $\mathrm{t}$ ' test $=0.58$

$\mathrm{p}=>0.05$ not significant

Telmisartan paired ' $\mathrm{t}$ ' test for diastolic $=7.69$ significant

Enalapril paired ' $\mathrm{t}$ ' test for diastolic $=7.73$ significant.

$\mathrm{p}=<0.05$ significant

Table 3: After 12 weeks systolic B.P. reduction in essential hypertensives.

\begin{tabular}{|llllll|}
\hline $\begin{array}{l}\text { Sr. } \\
\text { No. }\end{array}$ & $\begin{array}{l}\text { Systolic } \\
\text { BP } \\
\text { reduction }\end{array}$ & $\begin{array}{l}\text { Telmis } \\
\text { artan }\end{array}$ & $\%$ & $\begin{array}{l}\text { Enal } \\
\text { april }\end{array}$ & $\%$ \\
\hline 1 & Present & 17 & $85 \%$ & 14 & $70 \%$ \\
\hline 2 & Absent & 3 & $15 \%$ & 6 & $30 \%$ \\
\hline & & 20 & & 20 & \\
\hline
\end{tabular}

\section{$\chi 2-1.616$}

$\mathrm{p}=>0.05$ not significant

Systolic unpaired ' $\mathrm{t}$ ' test $=0.793$ not significant. $(\mathrm{p}>0.05)$

Telmisartan paired ' $\mathrm{t}$ ' test for systolic $=13.14$ significant $(\mathrm{p}<0.05)$

Enalapril paired ' $\mathrm{t}$ ' test for systolic $=15.64$ significant $(\mathrm{p}<0.05)$
Table 4: After 12 weeks diastolic B.P. reduction in essential hypertensives.

\begin{tabular}{|llllll|}
\hline $\begin{array}{l}\text { Sr. } \\
\text { No }\end{array}$ & $\begin{array}{l}\text { Diastolic } \\
\text { BP } \\
\text { reduction }\end{array}$ & $\begin{array}{l}\text { Telmis } \\
\text { artan }\end{array}$ & $\%$ & $\begin{array}{l}\text { Enalap } \\
\text { ril }\end{array}$ & $\%$ \\
\hline 1 & Present & 14 & $70 \%$ & 12 & $60 \%$ \\
\hline 2 & Absent & 6 & $30 \%$ & 8 & $40 \%$ \\
\hline & & 20 & & 20 & \\
\hline
\end{tabular}

$\chi 2-0.439, \mathrm{p}=>0.05$ not significant

Diastolic unpaired ' $\mathrm{t}$ ' test $=1.01 \mathrm{p}=>0.05$ not significant

Telmisartan paired ' $t$ ' test for diastolic $=17.6$ significant

Enalapril paired ' $\mathrm{t}$ ' test for diastolic $=6.72$ significant. $\mathrm{P}<0.05$ significant

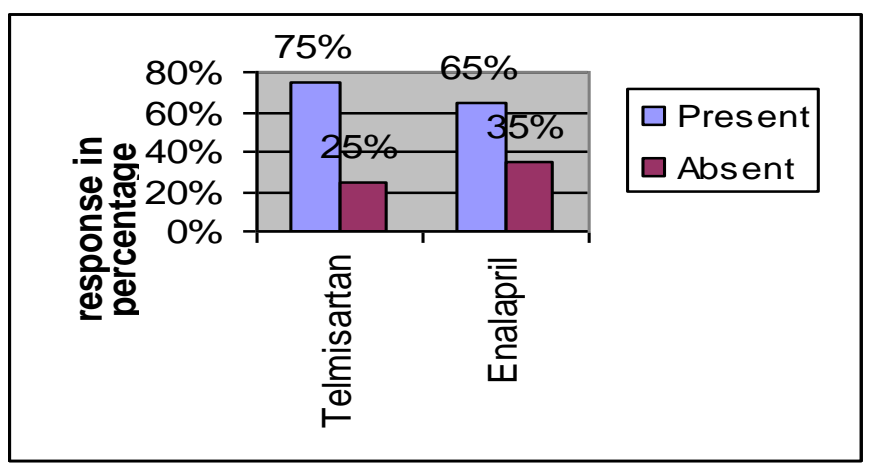

Figure 5: After 12 weeks systolic B.P. reduction in diabetic hypertensives.

$\chi 2-0.476$

$\mathrm{p}=>0.05$ not significant

Systolic unpaired ' $\mathrm{t}$ ' test $=0.670$ not significant. $(\mathrm{p}>0.05)$

Telmisartan paired ' $\mathrm{t}$ ' test for systolic $=10.5$ significant $(\mathrm{p}<0.05)$

Enalapril paired ' $\mathrm{t}$ ' test for systolic $=12.7$ significant $(\mathrm{p}<0.05)$

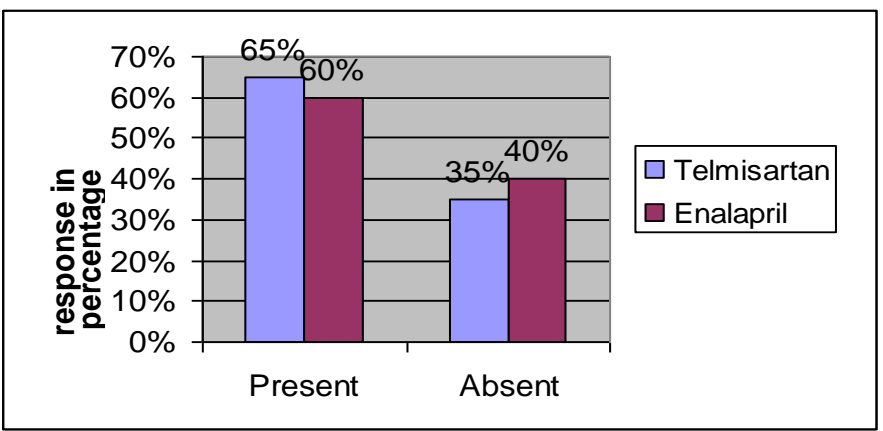

Figure 6: After 12 weeks diastolic B.P. reduction in diabetic hypertensives.

$\chi 2-0.106, p=>0.05$ not significant

Diastolic unpaired ' $\mathrm{t}$ ' test $=1.01$

$\mathrm{p}=>0.05$ not significant

Telmisartan paired ' $t$ ' test for diastolic $=17.6$ significant

Enalapril paired ' $\mathrm{t}$ ' test for diastolic $=6.72$ significant .

$\mathrm{p}=<0.05$ significant 


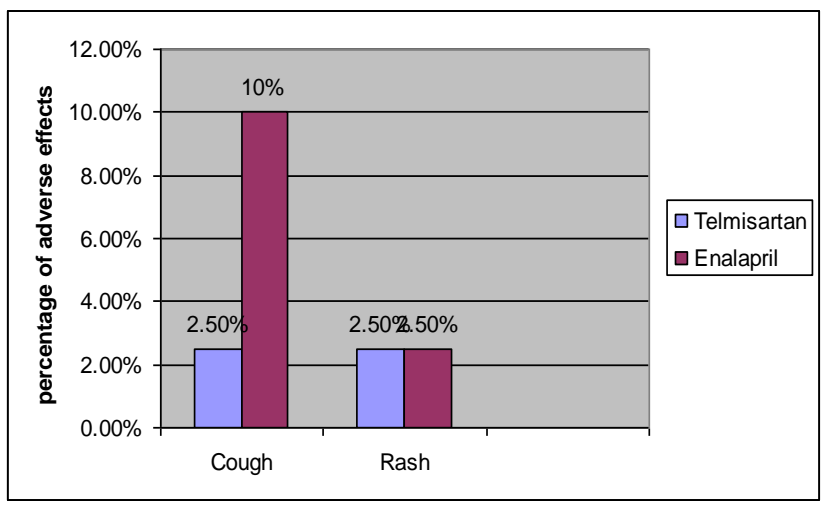

Figure 7: Percentage of adverse drug reactions.

Table 5: Prevalence of microalbuminuria after 12 weeks diastolic B.P. reduction in essential hypertensives.

\begin{tabular}{|lll|}
\hline Microalbuminuria & Telmisartan & Enalapril \\
\hline Essential hypertensives & 0 & $1(2.5 \%)$ \\
\hline Diabetic hypertensives & $1(2.5 \%)$ & $2(5 \%)$ \\
\hline Total & $1(2.5 \%)$ & $3(7.5 \%)$ \\
\hline
\end{tabular}

The prevalence of microalbuminuria is $2.5 \%$ in essential hypertension group (A) and $7.5 \%$ in diabetic hypertensive group (B) and there is no much change in the levels of microalbuminuria in both groups at the end of three months.

There are no significant changes in the results of biochemical and pathological investigations carried before and after completion of the study.

Fundus examination was normal in all cases before and after the study.

\section{DISCUSSION}

Hypertension is the most common cardiovascular disease responsible for $62 \%$ of cerebrovascular disease and $49 \%$ of ischemic heart disease with little variation by sex. The hypertension is the number one attributable risk factor for death accounting $20 \%$ of all deaths worldwide (nearly 10 million). The risk of developing cardiovascular complications is higher when the individual combines hypertension with other risk factors like obesity, diabetes mellitus, hypercholesterolemia / dyslipidemia or smoking. ${ }^{6}$ Hypertension is twice common in persons with diabetes mellitus. Elevated blood pressure is known to contribute to diabetic microvascular and macrovascular complications. $^{3}$

Though, we are unable to prevent these disorders we should be able to control these disorders and their complications with proper regular medication. As per latest BHS guidelines on the management of hypertension, we need to initiate, as first choice, either angiotensin converting enzyme inhibitor (ACEI) or angiotensin receptor blocker (ARB) in patients younger than 55 yrs.

Uncontrolled hypertension with diabetes leads to diabetic nephropathy which is the single most important cause for end stage renal disease (ESRD). Microalbuminuria will predict the ESRD in early stage. American Diabetic Association recommends that all patients with diabetes and hypertension be treated with ACEI/ARB to prevent and suppress ESRD.

Hence, the study was aimed to estimate the efficacy and tolerability of telmisartan in comparison with enalapril maleate in patients of Essential hypertension and Hypertension associated with diabetes mellitus. Many studies indicated similar efficacy profile for telmisartan and enalapril. More adverse effect profile was observed with enalapril maleate in comparison with telmisartan. This could be due to selective angiotensin II type 1, (AT1) receptor blockade by telmisartan.

Jouz, Xi Gel Y Nam HB, Zhou OF et al, 28 randomized control trials involving 5157 patients out of 721 studies on telmisartan have greater diastolic reduction than enalapril, (weighted mean difference 1.82, 95\% confidence interval 0.66 to 2.99). Telmisartan showed greater diastolic B.P. reduction than enalapril. Relative risk $(1.15,95 \%$ c.i.1.05 to 1.26$)$. Telmisartan had fewer drug related adverse events than enalapril (RR- 0.57c.u.i. 0.74). The meta-analysis indicates that telmisartan provides a superior B.P. Control to enalapril and better tolerability in hypertensive patients. ${ }^{4}$

JH Chen studied 147 patients of Taiwanese, mild to moderate essential hypertensives on telmisartan - 40mg, enalapril - 10mg once daily. Treatment period was 6 weeks. Telmisartan produced significant greater reduction from baseline in the primary end point diastolic BP compared with enalapril - 10mg. (11.7 Vs $8.7 \mathrm{mmHg}$ respectively, $\mathrm{p}=0.02$ ) Reduction from baseline SBP, DBP is more than $10 \mathrm{mmHg}$. Incidence of cough was $8.5 \%$ with telmisartan and $18.4 \%$ with enalapril. ${ }^{5}$

In diabetic hypertensives, Anthony $\mathrm{H}$ Burnett et al. reported $63 \%$ and $62 \%$ of patients who responded to telmisartan and enalapril respectively. As seen in this study, reduction of systolic BP was $85 \%$ in patients on telmisartan after 12 weeks, and diastolic BP reduction in $70 \%$ after 12 weeks. The decrease of systolic BP was $65 \%$ in patients on enalapril after 12 weeks, and diastolic BP reduction in $60 \%$ after 12 weeks. The results obtained from the both regimens were statistically not significant and were well tolerated.

Amerena J /ABPM comparison reported that in the 12 week study, diastolic B.P. in last 6hours of 24 hours dosing interval was $59 \%$ in telmisartan and $50 \%$ in enalapril group. Incidence of cough was $0.8 \%$ in telmisartan, $8.9 \%$ in enalapril, hypotension $1.1 \%$ in telmisartan and $3.9 \%$ in enalapril. In this study $85 \%$ 
showed systolic BP reduction in telmisartan group and $70 \%$ in enalapril group. Diastolic BP reduction was $70 \%$ in telmisartan group and in $60 \%$ enalapril. Adverse drug reactions were $2.5 \%$ in telmisartan group and $10 \%$ in enalapril group. ${ }^{6}$

L. Alocer et al. studied clinical efficacy and safety of telmisartan $80 \mathrm{mg}$ once daily, compared with enalapril $20 \mathrm{mg}$ once daily in patients with mild to moderate hypertension. In results of multi centre study, both systolic and diastolic blood pressures were decreased in both treatment groups but reductions were statistically different in favour of telmisartan (SBP $p=0.013$, DBP $p$ $=0.02)$. The incidence of adverse effects was lower in telmisartan group. ${ }^{\text {? }}$

After completion of the study period (3months), patients were requested to receive antihypertensive drugs routinely prescribed and dispensed at Government General Hospital, Vijayawada.

The patients who developed cough as adverse effect with studied drugs between 10-12 weeks were offered iron preparations and aspirin to suppress the cough. Patients were offered antihistaminic drugs to those who manifested rash. After completion of the study, patients were advised not to receive drugs which produce cough and urticaria.

By virtue of selective inhibition of angiotensin II type I receptor, very high lipophilicity and high volume of distribution, telmisartan reduces blood pressure throughout the day with high tolerability.

Recent studies have provided evidence that telmisartan might confer target organ protection in hypertension equal to and possibly better than other conventional antihypertensive agents including ACE inhibitors and other sartans.

Prevalence of microalbuminuria was observed in $2.5 \%$ of essential hypertensives and $7.5 \%$ of hypertension with diabetes patients. Hence, telmisartan offers advantage and represents an important new treatment option for hypertension with absence of cough. Telmisartan is effective, better tolerated than enalapril for the treatment of hypertension and has the advantage that it does not cause cough.

As per Joel M. Neutel, "morning" was defined as the period between 6-11.59am. Morning B.P. is a good assessment of whether the antihypertensive drug is providing smooth 24 hour B.P. control. "Early morning surge" is responsible for increased cardiovascular risk. Due to longest elimination half-life, high lipophilicity and slow dissociation kinetics, telmisartan provided 24 hours B.P. Control in their studies.

\section{Limitations of the study}

1. As the study was done with small sample size, the inference of the study has limited value.

2. Though dose ranges are high for studied drugs i.e., 20mg-80mg for telmisartan, 2.5-20mg for enalapril maleate, we offered fixed dose i.e., $40 \mathrm{mg}$ of telmisartan and $5 \mathrm{mg}$ of enalapril maleate to the studied patients.

3. In patients of microalbuminuria, to suppress microalbuminuria, we need to offer maximum dose of studied drugs after 2-3months of therapy. This work could not be carried out by me.

4. Casual blood pressure measurements taken in outpatients in teaching hospital may not necessarily represent blood pressure readings throughout the day.

In future, large studies are required on these drugs to explore antihypertensive property and microalbuminuria suppression activity and adverse effect profile at different doses for longer duration by monitoring ambulatory blood pressures.

\section{ACKNOWLEDGEMENTS}

We express our immense gratitude to our statistician and colleague postgraduate students for helping out in completing this study.

\section{Funding: No funding sources}

Conflict of interest: None declared

Ethical approval: The study was approved by the institutional ethics committee

\section{REFERENCES}

1. National High Blood Pressure Education Program Working Group report on hypertension in diabetes. Hypertension. 1994 Feb;23(2):145-58.

2. BHS Clinical guidelines CG34; Management of hypertension in adults in primary care. 2010. Available http://www.nice.org.uk/nicemedia/pdf/CG034NICEg uideline.pdf. Accessed June 2010.

3. Libby P, Nathan DM, Abraham K, Brunzell JD. Report of the National Heart, Lung and Blood Institute: National Institute of Diabetes and Digestive and Kidney Diseases Working Group on Cardiovascular Complications of DM. Circulation. 2005;111:3489-93.

4. Zou Z, Xi GL, Yuan HB, Zhu QF, Shi $X Y$. Telmisartan versus angiotension-converting enzyme inhibitors in the treatment of hypertension: a meta-analysis of randomized controlled trials. Journal of Human Hypertension. 2009;23(5):339-49. 
5. Chen JH, Cheng JJ, Chen CY, Chiou HC, Huang TY, Tsai CD, Fu MM, Cherng WJ. Comparison of the efficacy and tolerability of telmisartan $40 \mathrm{mg}$ vs. enalapril $10 \mathrm{mg}$ in the treatment of mild-to-moderate hypertension: a multicentre, double-blind study in Taiwanese patients. Int J Clin Pract Suppl. 2004Dec;(145):29-34.

6. Amerena J, Pappas S, Ouellet JP, Williams L, O'Shaughnessy D.ABPM comparison of the antihypertensive profiles of telmisartan and enalapril in patients with mild-to-moderate essential hypertension. J Int Med Res. 2002NovDec;30(6):543-52.

7. L Alcocer, $\mathrm{P}$ Fernandez-Bonetti, E Campos, R Dominguez-Henkel, J J de la Fuente, C SegoviaAyala Clinical efficacy and safety of telmisartan 80 mg once daily compared with enalapril $20 \mathrm{mg}$ once daily in patients with mild-to-moderate hypertension: results of a multicentre study. Int J Clin Pract Suppl. 2004 Dec;(145):23-8. 15617455 Cit:2.

8. Lacourcière Y, Neutel JM, Davidai G, Koval S.A multicenter, 14-week study of telmisartan and ramipril in patients with mild-to-moderate hypertension using ambulatory blood pressure monitoring. Am J Hypertens. 2006 Jan;19(1):104-12.

9. Smith DH. Treatment of hypertension with an angiotensin II-receptor antagonist compared with an angiotensin-converting enzyme inhibitor: a review of clinical studies of telmisartan and enalapril. Clin Ther. 2002Oct;24(10):1484-501.

10. Karlberg BE, Lins LE, Hermansson K. Efficacy and safety of telmisartan, a selective AT1 receptor antagonist, compared with enalapril in elderly patients with primary hypertension. TEES Study Group. 1999 Feb;17(2):293-302.

11. Laverman G, Ruggenenti P, Remuzzi G. Angiotensin-converting enzyme inhibition or angiotensin receptor blockade in hypertensive diabetics? Curr Hypertens Rep. 2003Oct;5(5):364-7.

12. Frida Liane Plavnik and Artur Beltrame Ribeiro. A Multicenter, Open-Label Study of the Efficacy and Safety of Telmisartan in Mild to Moderate Hypertensive Patients Arq. Bras. Cardiol. São Paulo. 2002Oct;79(4):339-50.

13. Laurence L. Brunton, John S. Lazo, Keith L ParkerGoodmann and Gilman-The pharmacological basis of theraupetics. $11^{\text {th }}$ ed. USA: Mc Graw-Hill companies; 2006: 802,808 and 809.

14. Bakris GL, Williams M, Dworkin L, Elliott WJ, Epstein M, Toto R, Tuttle K, Douglas J, Hsueh W, Sowers J. Preserving renal function in adults with hypertension and diabetes: a consensus approach. National Kidney Foundation Hypertension and Diabetes Executive Committees Working Group. Am J Kidney Dis. 2000 Sep;36(3):646-61.

doi:10.5455/2319-2003.ijbcp20140225

Cite this article as: Ch J, Kambar C, Kurli S.

Comparative study of efficacy and adverse effects profile of telmisartan vs enalapril maleate in patients of essential hypertension and diabetic hypertensives. Int J Basic Clin Pharmacol 2014;3:194-200. 